\title{
Gastro-Protective Effect of Lactoferrin Purified From Cheese Whey and Marjoram Tea Against Indomethacin- Induced Gastric Ulcers
}

\author{
Ahmed M. Abdel-Salam ${ }^{1}$ (D), Ahmed H. Zaghloul ${ }^{1}$, Rasha S. Mohamed ${ }^{2, *}$ (D) \\ 1 Dairy Science Department, National Research Centre, Dokki, Cairo, Egypt; amsalam68@hotmail.com (A.M.A.-S.)); \\ zaghloul55.az@gmail.com (A.H.Z.); \\ 2 Department of Nutrition and Food Sciences, National Research Centre, Dokki, Cairo, Egypt; smarasha2005@yahoo.com \\ (R.S.M.); \\ * Correspondence: smarasha2005@yahoo.com (R.S.M.);
}

Scopus Author ID 57204599407

Received: 7.03.2021; Revised: 8.04.2021; Accepted: 11.04.2021; Published: 19.04.2021

\begin{abstract}
The current study investigated lactoferrin's gastro-protective effect purified from cheese whey and marjoram tea against indomethacin-induced gastric ulcers in rats. Pre-treatment with lactoferrin, marjoram tea, or their combination was conducted for 21 days before introducing gastric ulcers (by a single oral treatment of $30 \mathrm{mg} / \mathrm{kg}$ indomethacin). Ulcer index, serum parameters (erythrocyte sedimentation rate, hemoglobin, iron, total iron-binding capacity, lactate dehydrogenase activity, and ferritin), and stomach inflammatory markers (Tumor necrosis factor-alpha and nitric oxide) as well as oxidative markers (malondialdehyde, reduced glutathione, and superoxide dismutase) were assessed. Also, the pathological changes were examined. The pre-treatment with lactoferrin either along with marjoram tea or alone promisingly inhibited the ulcer (77.97 and $60.96 \%$, respectively). Lactoferrin, marjoram tea, or their combination suppressed the elevation of lactate dehydrogenase activity, ferritin, tumor necrosis factor-alpha, nitric oxide, and malondialdehyde and the reduction of reduced glutathione and superoxide dismutase. The pathological findings revealed that lactoferrin either along with marjoram tea or alone promisingly prevented stomach tissue ulceration. The obtained results suggested the gastro-protective effect of lactoferrin purified from cheese whey and marjoram tea against indomethacin-induced gastric ulcers via their anti-inflammatory and antioxidant activity.
\end{abstract}

Keywords: Lactoferrin; marjoram; gastric ulcer; indomethacin.

(C) 2021 by the authors. This article is an open-access article distributed under the terms and conditions of the Creative Commons Attribution (CC BY) license (https://creativecommons.org/licenses/by/4.0/).

\section{Introduction}

Gastric ulcer is one of the most prevalent peptic ulcer diseases [1, 2]. In addition to the pain and complications associated with the gastric ulcer, it also causes bleeding and may lead to death, albeit in insignificant numbers at the global level. [3, 4]. It is the inevitable consequence of exceeding destructive than defensive factors in the stomach. The destructive factors include high intake of fatty foods and alcohol, excessive intake of nonsteroidal antiinflammatory drugs (NSAIDs), smoking in addition to the Helicobacter pylori infection, while the defensive factors include antioxidant enzymes, nitric oxide, mucin production, surface phospholipids, prostaglandins in addition to growth factors [5]. The current medications of gastric ulcers, including proton pump inhibitors, H2-receptor blockers, and others, may exhibit various side effects in addition to the incidence of relapse and tolerance [6]. Hence, scientific 
validation of protective natural agents against gastric ulcers may offer an effective opportunity to avoid the side effects of conventional therapies [1].

Lactoferrin (LF) is known as iron-binding multifunctional glycoprotein produced by exocrine glands and by neutrophils and contributes to the host defenses. Human and bovine lactoferrin has the same sequence homology and similar functions. LF inhibits bacterial growth either via the iron-binding ability or via inhibition of the bacterial adhesion. Also, LF possesses an anti-inflammatory effect [7]. LF is also present in camel milk [8]. Recent studies investigated and recommended LF as a protective agent and cure for COVID-19 [9]. LF can use as an effective treatment of Helicobacter pylori [10].

Marjoram (Origanum majorana), also known as sweet marjoram, is a famous plant utilized in folk medicine. Marjoram plant and their extracts exhibit potent antioxidant activity [11]. The antioxidant of marjoram can be attributed to the high content of phenolic compounds and flavonoids [12]. Çelik et al. [13] attributed the antioxidant effect of marjoram to the high content of rosmarinic acid, apigenin, caffeic acid, and rutin. Flavonoids, along with their antiinflammatory and antioxidant properties, help prevent and treat stomach ulcers $[2,3]$.

This work aimed to evaluate and study the gastroprotective effect of lactoferrin purified from cheese whey and marjoram tea against indomethacin-induced gastric ulcers.

\section{Materials and Methods}

\subsection{Materials.}

Marjoram was purchased from a local farm, Giza, Egypt. Cheese whey powdered $(3.25 \%$ moisture, $0.5 \%$ total fat, $65 \%$ total carbohydrates, $11 \%$ protein, and $8.5 \%$ total ash) was purchased from Bahçıvan Co., Turkey. Chemicals and pure reagents were purchased from Sigma Chemical Companies (Sigma-Aldrich, St. Louis, MO, USA).

\subsubsection{Animals.}

Male Wistar rats (12 weeks old) of $196.5 \pm 9.85 \mathrm{~g}$ as mean \pm SD were obtained from the animal house of the National Research Centre, Cairo, Egypt. Animals were kept individually in stainless steel cages under standard laboratory conditions $\left(23-25{ }^{\circ} \mathrm{C}, 12 \mathrm{~h}\right.$ light/dark cycle) and free access to diet and water. According to the Medical Research Ethics Committee, National Research Centre, Cairo, Egypt, this study has been carried out and followed the recommendations of the National Institutes of Health Guide for Care and Use of Laboratory Animals (Publication No. 85-23, revised 1985).

\subsubsection{Animals' diet.}

Balanced diet (12\% protein supplemented from casein, 10\% corn oil, 10\% sucrose, $58.5 \%$ maize starch, $5 \%$ fiber, $3.5 \%$ salt mixture, and $1 \%$ vitamin mixture), salt, and vitamin mixtures were prepared in accordance with AIN-93 [14].

\subsection{Methods.}

2.2.1. Isolation of bovine lactoferrin from cheese whey.

The cheese whey samples have been dissolved and standardized to attain $20 \%$ total solids. Lactoferrin was isolated from cheese whey according to the method described by Abdel- 
Salam et al. [15]. The bovine whey samples were adjusted to $\mathrm{pH} 7$ by dropwise of $2 \mathrm{~N} \mathrm{NaOH}$. Carboxy Methyl (CM)-Sephadex C-50 resin was hydrated and washed extensively in deionized water prior to use, then the moist CM-Sephadex C-50 was added and stirred gently using a magnetic stirrer Device at room temperature. The bovine whey- resin mixture was then transferred to a Buchner funnel and flask, and the spent whey recovered under a gentle vacuum. The resin washed with distilled water, followed by elution of bound lactoferrin with sodium chloride. The pooled elute of lactoferrin was adjusted to calculated volume with deionized water, and the extra salts were removed using dialysis techniques. The bovine lactoferrin extract was stored at $-20^{\circ} \mathrm{C}$ until use.

\subsubsection{Detection of lactoferrin purified from cheese whey using liquid chromatography.}

The lactoferrin purified from cheese whey was determined according to the method described by Abel-Salam et al. [16] using Waters Liquid chromatography equipped with Waters-600 E Multisolvent Delivery System and Waters Millennium program. The detection of bovine lactoferrin carried out using Waters 484 variable wavelength detector and reverse phase-HPLC- C18 column with $0.1 \%$ TFA in water and acetonitrile. The wavelength detection was at $280 \mathrm{~nm}$. Bovine lactoferrin standard (Sigma, USA) was dissolved in HPLC mobile phase with known concentration, and $20 \mu \mathrm{l}$ was injected at the same condition as the samples. Bovine lactoferrin sample was detected and quantified by comparing peak areas of unknown samples with those of corresponding bovine lactoferrin standard solutions using the WatersMillennium Data System Program.

\subsubsection{Marjoram tea preparation.}

Marjoram tea was prepared using the method described by Fecka and Turek [17]. The marjoram plant material was allowed to air drying and afterward pulverized in a grinder. Briefly, fifty grams of powder placed in a flask ( $2 \mathrm{~L})$ with $1000 \mathrm{ml}$ of distilled water and boiled for $15 \mathrm{~min}$. The mixture was filtered twice, first through cheese-cloth (50\% cotton $150 \%$ polyester) and then through filter paper (Whatman No.2). The marjoram tea was preserved in sterile dark bottles $(500 \mathrm{ml})$ in a cool environment $\left(4^{\circ} \mathrm{C}\right)$ until further use.

\subsubsection{Evaluation of the gastro-protective effect.}

Thirty rats were divided after one-week acclimatization into five groups $(n=6)$ as follows:

G1: The control group where rats were daily orally given distilled water.

G2: Indomethacin group (IND) where the gastric ulcer was induced in fasted rats on the $22^{\text {nd }}$ day by oral administration of indomethacin $(30 \mathrm{mg} / \mathrm{kg})$ dissolved in $5 \%$ sodium bicarbonate [18].

G3: Lactoferrin + indomethacin group (LF+IND) where rats were pre-treated daily with lactoferrin $(1 \mathrm{ml})$ for 21 days, then the gastric ulcer was induced in fasted rats on the $22^{\text {nd }}$ day by oral administration of indomethacin $(30 \mathrm{mg} / \mathrm{kg})$ dissolved in $5 \%$ sodium bicarbonate.

G4: Marjoram tea + indomethacin group (MT+IND) where rats were daily pre-treated with the marjoram tea $(1 \mathrm{ml})$ for 21 days, then the gastric ulcer was induced in fasted rats on the $22^{\text {nd }}$ day by oral administration of indomethacin $(30 \mathrm{mg} / \mathrm{kg})$ dissolved in $5 \%$ sodium bicarbonate.

G5: Lactoferrin + marjoram tea + indomethacin group (LF+MT+IND) where rats were daily pre-treated with a freshly prepared mixture of lactoferrin and marjoram tea $(1 \mathrm{ml})$ for 21 days, 
then the gastric ulcer was induced in fasted rats on the $22^{\text {nd }}$ day by oral administration of indomethacin $(30 \mathrm{mg} / \mathrm{kg})$ dissolved in $5 \%$ sodium bicarbonate.

All rats were fed on a balanced diet all over the study period. At the end of the study, total food intake, body weight gain, and feed efficiency ratio were calculated.

\subsubsection{Blood analysis.}

Twenty-four hours after administration of indomethacin, blood was collected from each rat under slight anesthesia. A portion of the whole blood was analyzed for erythrocyte sedimentation rate (ESR) and hemoglobin ( $\mathrm{Hb})$ according to Drabkin [19], and the remaining blood was centrifugated for $10 \mathrm{~min}$ at $1000 \mathrm{~g}$ and serum of each rat was kept under $-20{ }^{\circ} \mathrm{C}$ until used. Serum iron, total iron-binding capacity (TIBC), and lactate dehydrogenase (LDH) activity were determined according to Stookey [20], Betts and Stuart [21], and Zimmerman et al. [22], respectively. Serum ferritin was determined using Eliza kit (Glory Science Co., Ltd. China)

\subsubsection{Measurement of ulcer index.}

Rats were killed via decapitation, and the stomach was immediately separated from each rat and photographed. The ulcerated surface in each stomach was measured with a transparent millimeter-scale rule. The ulcer index (U.I) for each animal was calculated using the following equation [23]:

$$
\text { U.I. }=[\text { ulcerated area/total stomach area }] \times 100 .
$$

while the percentage of inhibition against ulceration was determined using the following equation:

$\%$ Ulcer inhibition $=[$ U.I. in control - U.I. in test $] \times 100 /$ U.I. in control.

\subsubsection{Stomach homogenate analysis.}

Part of each rat's stomach was used in the histopathological examination, and the homogenate of the other part immediately analyzed for malondialdehyde (MDA), nitric oxide (NO), and reduced glutathione (GSH), according to Ohkawa et al. [24] Montgomery and Dymock [25] and Sedlak and Lindsay [26], respectively. Also, stomach tumor necrosis factor$\alpha$ (TNF- $\alpha$ ) and superoxide dismutase (SOD) were determined using Eliza kits (SinoGeneclon Biotech Co., Ltd).

\subsubsection{Histopathological studies.}

Tissue samples of stomach fixed in $10 \%$ formal saline were further processed for pathological examination using the automatic tissue processor and sectioned at $5 \mu \mathrm{m}$ thickness by using the rotary microtome. Sections were stained with Hematoxylin and Eosin (H \& E) for microscopical examination. The sections were examined using a Nikon research microscope.

\subsubsection{Statistical analysis.}

Statistical analysis was done using SPSS version 16. The results were expressed as mean \pm standard error (SE) and analyzed statistically using a one-way analysis of variance (ANOVA) followed by the Duncan test. The statistical significance of difference was taken as $P \leq 0.05$. 


\section{Results and Discussion}

As shown in Figure 1, the lactoferrin sample isolated from cheese whey was separated using reversed-phase high-performance liquid chromatography (RP-HPLC) by reverse phaseHPLC-C18 Column with $0.1 \%$ TFA in water and acetonitrile. The peak of lactoferrin isolated from cheese whey was detected compared with the bovine lactoferrin standard (sigma). The peak of lactoferrin isolated from cheese whey appeared in the same retention time as the peak of bovine lactoferrin standard (sigma).

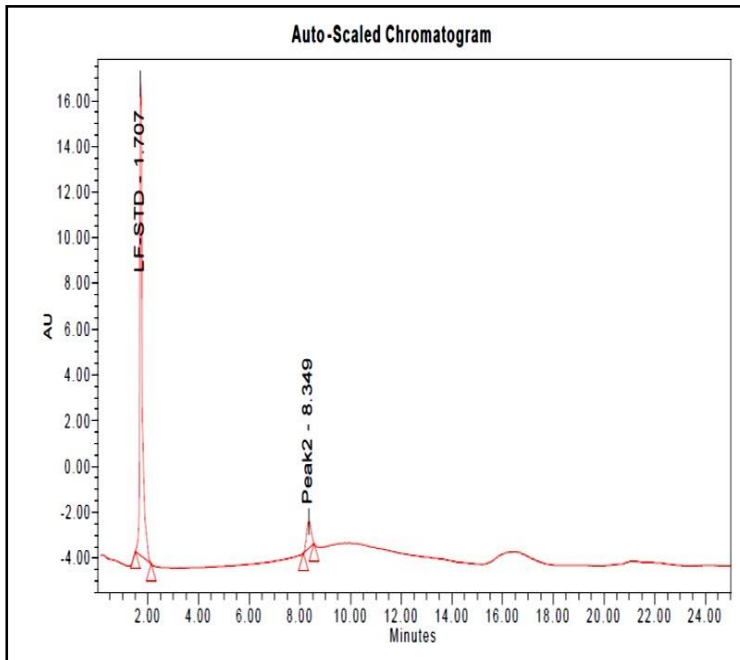

(A) Bovine lactoferrin standard (sigma)

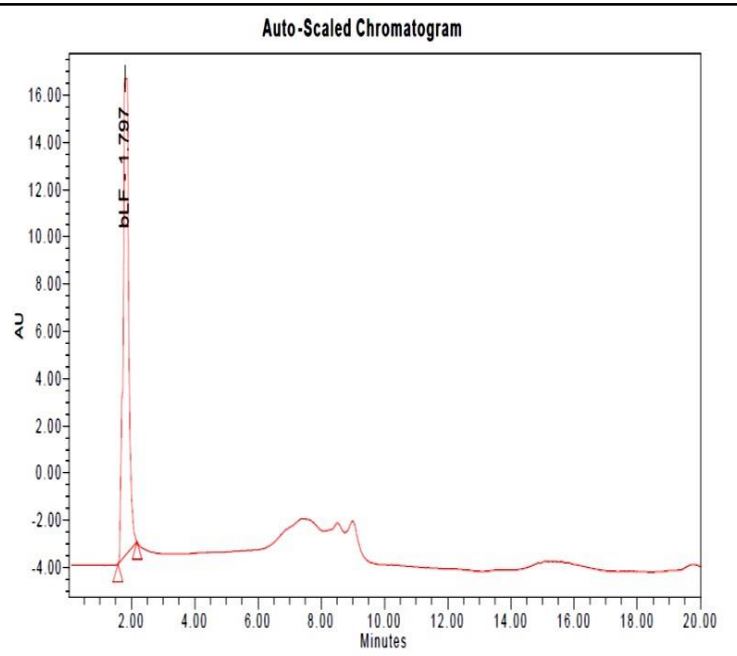

(B) Lactoferrin isolated from cheese whey

Figure 1. HPLC-Chromatograms of (A) Bovine lactoferrin standard; (B) lactoferrin isolated from cheese whey.

Nonsteroidal anti-inflammatory drugs (NSAIDs) can cause gastric ulcers through gastric mucosal cell damage, which develops due to the elevated mucosal permeability of active radicals, reduced blood flow, and damage of endothelial cells. The elevation of mucosal permeability results in low-grade inflammation [27]. To study the gastro-protective effect of lactoferrin and marjoram tea in the present work, indomethacin, as one of the NSAIDs, was used to induce gastric ulcers in rats indomethacin causes ulcers in various parts of the gastrointestinal tract $[28,29]$. It was reported that indomethacin inhibits the two isoforms of the COX enzyme, causes severe damage in gastric tissue, and elevates lipid peroxidation in addition to its ability to generate ROS [30,31]. According to Sabiu et al. [18], the ulcer scores can be graded from 0 to 5 based on the injury's severity. From the stomachs' photographs of different groups (Figure 2), it can be observed that the stomach of the control rat (Figure 2A) was normal (score $=0$ ). The stomach of IND rats (Figures $2 \mathrm{~B} 1$ and $2 \mathrm{~B} 2$ ) showed very severe lesions (score $=4$ ), while the stomach of rats that pre-treated with lactoferrin (Figure 2C) before ulcer induction showed almost normal mucosa (score $=0$ ). The stomach of rats pre-treated with marjoram tea (Figure 2D) before ulcer induction showed one or two lesions (score $=2$ ), while the stomach of rats pre-treated with lactoferrin and marjoram tea (Figure 2E) before ulcer induction showed almost normal mucosa (score $=0$ ).

Ulcer index was assessed in IND, LF+IND, MT+IND, and LF+MT+IND groups, and the percentage of inhibition was assessed in LF+IND, MT+IND, and LF+MT+IND groups. The ulcer index was found to be increased in the IND group while the pre-treatment with lactoferrin, marjoram tea, or their mixture suppressed the ulcer index's elevation (Figure 3A). 


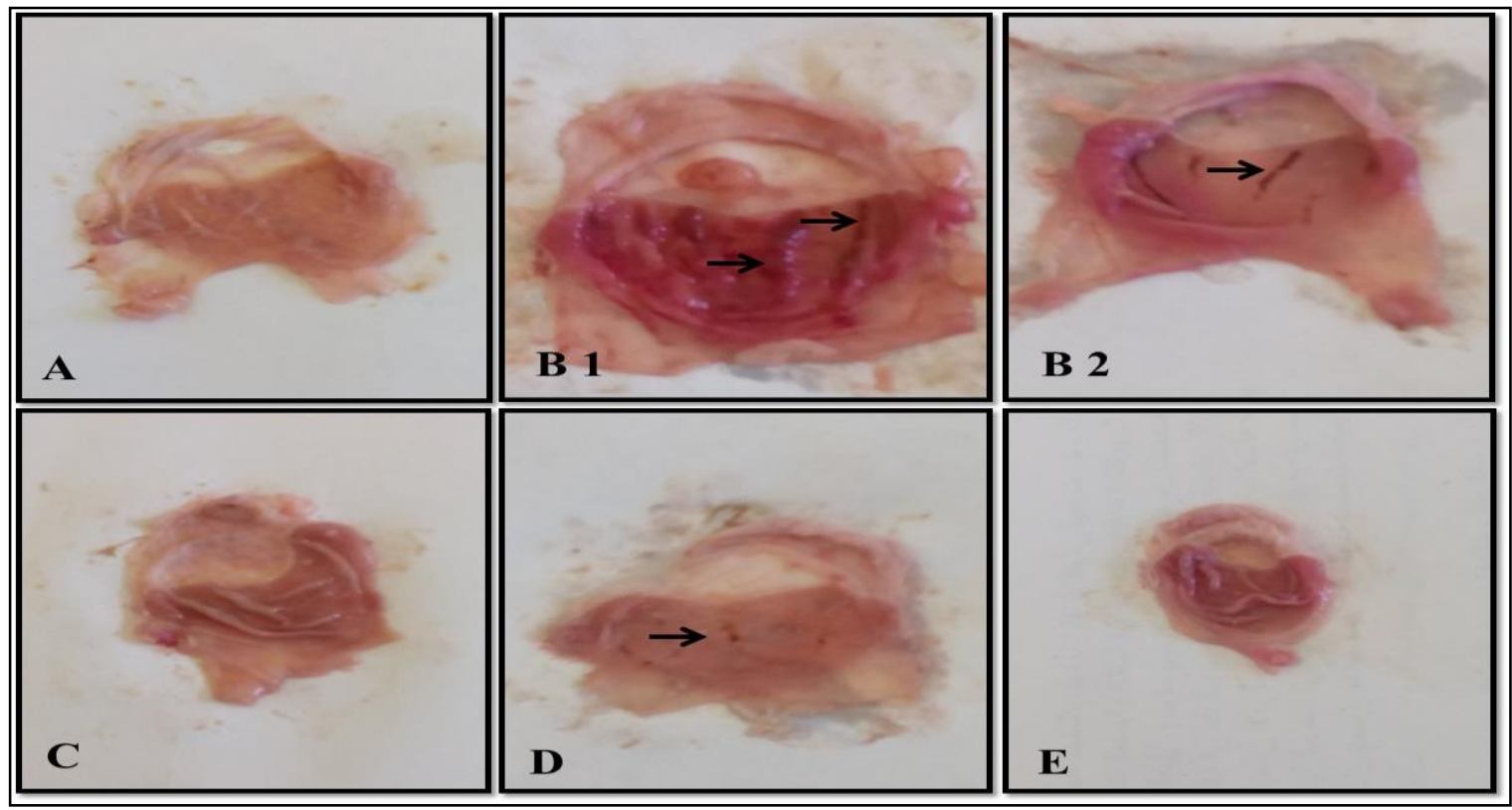

Figure 2. Stomachs' photographs of different groups (A) Stomach of control rat; (B1 and B2) Stomach of rat treated with indomethacin showing mucosa with hemorrhagic erosion (arrows); (C) Stomach of rat that pretreated with lactoferrin before ulcer induction showing normal mucosa; (D) Stomach of rat that pre-treated with marjoram tea before ulcer induction showing slight hemorrhagic erosion (arrows); (E) Stomach of rat that pretreated with lactoferrin and marjoram tea before ulcer induction showing normal mucosa.

The pre-treatment with the mixture of lactoferrin and marjoram tea was superior in inhibiting the gastric ulcer (Fig. 3B). The gastro-protective effect of lactoferrin, marjoram tea, and their mixture against indomethacin-induced gastric ulcers may be attributed to their antiinflammatory and antioxidant effects. Lepanto et al. [32] reported the anti-inflammatory effect of lactoferrin. The antioxidant and anti-inflammatory effect of marjoram tea may be attributed to the presence of polyphenols compounds [17]. Pimple et al. [33] found that $400 \mathrm{mg} / \mathrm{kg}$ marjoram tea (prepared with cold water for $24 \mathrm{~h}$ ) inhibited the ulcer induced by aspirin in diabetic rats with $22.38 \%$.

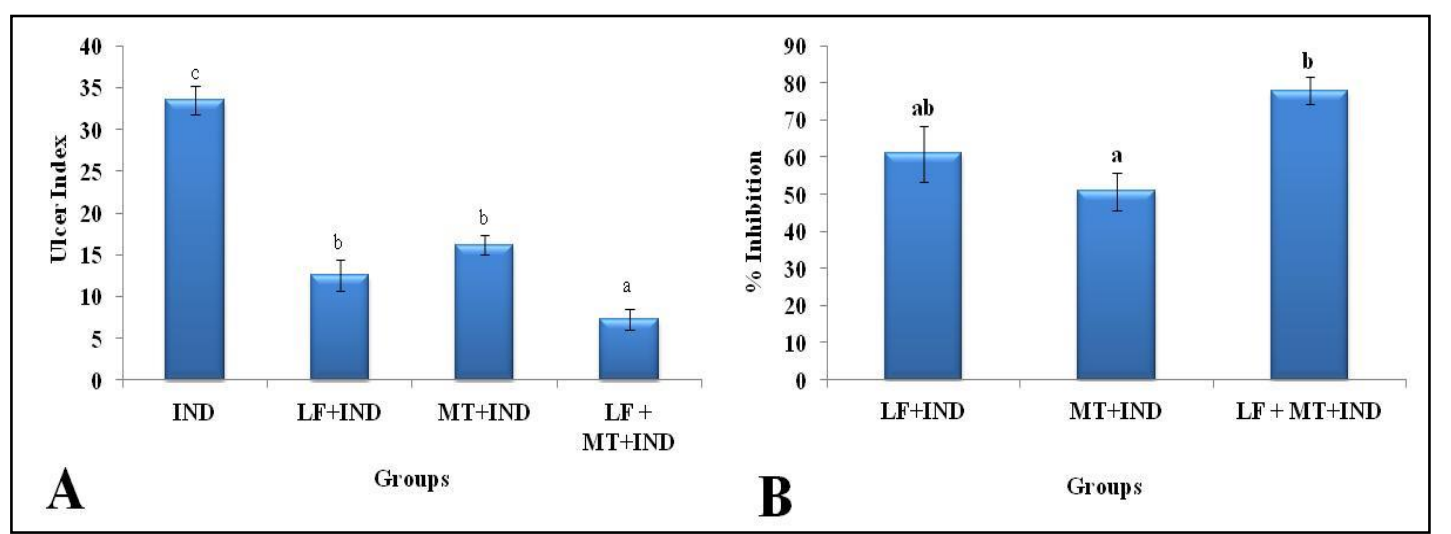

Figure 3. Ulcer index and \% inhibition of different groups. (A) ulcer index after different treatments; (B) the percentage of ulcer inhibition of different treatments. The values are expressed as the means $\pm S E(n=6)$. Different superscript letters on each par indicate a significant difference at $\mathrm{P} \leq 0.05$. IND, indomethacin; $\mathrm{LF}$, lactoferrin; MT, marjoram tea.

Although non-ulcerated and ulcerated rats consumed almost similar amounts of food, the bodyweight gain was found to be significantly decreased in the IND group (Table 1). 
Table 1. Nutritional parameters of non-ulcerated and ulcerated groups.

\begin{tabular}{l|c|c|c|c|c}
\multirow{2}{*}{ Parameters } & \multicolumn{7}{c}{ Groups } & LF+MT+IND \\
\cline { 2 - 6 } & $\begin{array}{c}\text { Control } \\
\text { normal }\end{array}$ & IND & LF+IND & MT+IND & \\
\hline Initial body weight $(\mathbf{g})$ & $196.67^{\mathrm{a}} \pm 3.22$ & $196.50^{\mathrm{a}} \pm 5.09$ & $196.33^{\mathrm{a}} \pm 4.34$ & $196.50^{\mathrm{a}} \pm 3.54$ & $196.67^{\mathrm{a}} \pm 5.11$ \\
\hline Final body weight $(\mathbf{g})$ & $270.67^{\mathrm{a}} \pm 3.17$ & $255.67^{\mathrm{a}} \pm 5.65$ & $267.50^{\mathrm{a}} \pm 8.00$ & $259.17^{\mathrm{a}} \pm 4.80$ & $268.17^{\mathrm{a}} \pm 10.50$ \\
\hline Body weight gain $(\mathbf{g})$ & $74.00^{\mathrm{b}} \pm 4.55$ & $59.17^{\mathrm{a}} \pm 2.62$ & $71.17^{\mathrm{a} b} \pm 4.15$ & $62.67^{\mathrm{a}} \pm 2.70$ & $71.50^{\mathrm{ab}} \pm 6.12$ \\
\hline Total food intake $(\mathbf{g})$ & $396.33^{\mathrm{a}} \pm 3.90$ & $382.17^{\mathrm{a}} \pm 8.52$ & $379.67^{\mathrm{a}} \pm 12.43$ & $387.83^{\mathrm{a}} \pm 6.36$ & $384.50^{\mathrm{a}} \pm 5.19$ \\
\hline Feed efficiency ratio & $0.19^{\mathrm{a}} \pm 0.01$ & $0.15^{\mathrm{a}} \pm 0.01$ & $0.19^{\mathrm{a}} \pm 0.01$ & $0.16^{\mathrm{a}} \pm 0.01$ & $0.19^{\mathrm{a}} \pm 0.01$
\end{tabular}

The values are expressed as the means $\pm S E(n=6)$. Different superscript letters in each row indicate a significant difference at $\mathrm{P} \leq 0.05$. IND, indomethacin; $\mathrm{LF}$, lactoferrin; MT, marjoram tea.

Regarding the serum parameters of non-ulcerated and ulcerated groups (Table 2), ESR, $\mathrm{LDH}$, and ferritin were significantly elevated in the IND group compared to normal rats. The elevated ESR indicates inflammation [34]. Elevation of LDH activity in the current results is coinciding with Goineau and Castagné [35], who confirmed the release of LDH due to indomethacin-induced cell damage. Elevation of ferritin in the IND group may be attributed to the cell damage induced by indomethacin. Kell and Pretorius [36] reported that cell damage results in ferritin infiltration into the serum, missing the iron on the way. Hence, iron in an unbonded form can promote further cell damage. This also interprets the slight increase in serum iron concentration in the IND group. The pre-treatment of lactoferrin, marjoram tea, or their mixture suppressed the elevation in ESR, LDH, and ferritin. Although there was no significant change in $\mathrm{Hb}$ concentration among normal and IND groups, the pre-treatment with lactoferrin either alone or with marjoram tea significantly increased the $\mathrm{Hb}$ concentration. Pulina et al. [37] found that injection of lactoferrin elevated hemoglobin concentration in acute anemic rats. There was no significant change in TIBC level among different groups while a slight increase, not statistically significant, in iron was recorded by the IND group when compared to other groups. However, lactoferrin catalyzes the absorption of iron in the iron-deficiency state, lactoferrin chelates the excessive iron. Hence, LF protects the body from excessive ironinduced damage [38]. Reported that LF increased hemoglobin and iron in suckling piglets [39].

Table 2. Serum parameters of non-ulcerated and ulcerated groups.

\begin{tabular}{l|c|c|c|c|c}
\multirow{2}{*}{ Parameters } & \multicolumn{5}{c}{ Groups } \\
\cline { 2 - 6 } & Control normal & IND & LF+IND & MT+IND & LF+MT+IND \\
\hline ESR $(\mathbf{m m} / \mathbf{h})$ & $1.83^{\mathrm{a}} \pm 0.31$ & $6.83^{\mathrm{c}} \pm 0.40$ & $2.83^{\mathrm{ab}} \pm 0.31$ & $3.50^{\mathrm{b}} \pm 0.43$ & $2.33^{\mathrm{a}} \pm 0.49$ \\
\hline $\mathbf{L D H}(\mathbf{U} / \mathbf{l})$ & $234.70^{\mathrm{a}} \pm 15.99$ & $339.55^{\mathrm{c}} \pm 12.51$ & $256.55^{\mathrm{ab}} \pm 13.51$ & $289.88^{\mathrm{b}} \pm 13.56$ & $254.02^{\mathrm{a}} \pm 12.16$ \\
\hline $\mathbf{H b}(\mathbf{g} / \mathbf{d l})$ & $13.14^{\mathrm{a}} \pm 0.39$ & $13.07^{\mathrm{a}} \pm 0.53$ & $14.71^{\mathrm{b}} \pm 0.37$ & $13.37^{\mathrm{a}} \pm 0.34$ & $14.50^{\mathrm{b}} \pm 0.23$ \\
\hline Iron $(\mathbf{m g} / \mathbf{d l})$ & $221.02^{\mathrm{a}} \pm 8.10$ & $230.76^{\mathrm{a}} \pm 7.02$ & $222.82^{\mathrm{a}} \pm 5.43$ & $228.53^{\mathrm{a}} \pm 9.71$ & $221.80^{\mathrm{a}} \pm 5.98$ \\
\hline TIBC $(\boldsymbol{\mu g} / \mathbf{d l})$ & $70.01^{\mathrm{a}} \pm 0.92$ & $70.28^{\mathrm{a}} \pm 1.00$ & $68.83^{\mathrm{a}} \pm 1.14$ & $70.26^{\mathrm{a}} \pm 0.67$ & $69.51^{\mathrm{a}} \pm 0.94$ \\
\hline Ferritin $(\mathbf{n g} / \mathbf{m l})$ & $73.55^{\mathrm{a}} \pm 2.71$ & $80.06^{\mathrm{b}} \pm 0.69$ & $76.06^{\mathrm{ab}} \pm 2.26$ & $79.70^{\mathrm{ab}} \pm 0.49$ & $73.40^{\mathrm{a}} \pm 2.75$
\end{tabular}

The values are expressed as the means \pm SE $(n=6)$. Different superscript letters in each row indicate a significant difference at $\mathrm{P} \leq 0.05$. IND, indomethacin; LF, lactoferrin; MT, marjoram tea.

Table 3 represents the parameters assessed in the stomach homogenate. Significant elevations in TNF- $\alpha$, NO, and MDA compared to normal rats were observed in the IND group. GSH and SOD significantly decreased in the IND group in comparison to normal rats. The pre-treatment of lactoferrin, marjoram tea, or their mixture suppressed either the elevation in TNF- $\alpha$, NO, and MDA or reduced GSH and SOD. Kim et al. [40] found that lactoferrin reduced TNF- $\alpha$ and exhibited an anti-inflammatory effect. The ameliorative effect of lactoferrin on oxidative markers (MDA, GSH, and SOD) may be attributed to lactoferrin's ability to prevent the formation of free radicals. Kell et al. [41] mentioned that after lysis of erythrocytes, serum ferroxidase ceruloplasmin could transfer iron to lactoferrin which prevents 
the generation of hydroxyl radicals in the healthy person. Also, Wang et al. [42] confirmed that bovine lactoferrin's intake elevated the activity of glutathione peroxidase and superoxide dismutase in the piglets via the regulation of mRNA expressions of these enzymes. Han et al. [43] reported that bovine LF reduces the inflammation and oxidative markers in the lung. Fecka and Turek [17] reported that caffeic acid derivatives, including rosmarinic acid, glycosides of luteolin, and hydroquinone are among the phenolic content of marjoram tea (prepared with hot water) and to which the antioxidant effect of marjoram tea can be attributed. LF is considered an effective treatment of iron deficiency anemia [44]. Whether the main cause of the ulcers is Helicobacter pylori infection or the use of nonsteroidal anti-inflammatory drugs, people with stomach ulcers suffer from abdominal pain [45] and iron deficiency anemia $[46,47]$. Therefore, it is assumed that marjoram tea, as a treatment for stomach upset, along with lactoferrin, as a treatment for anemia, may be useful in gastric ulcer and related anemia. So, further studies are required to assess marjoram tea's effect along with lactoferrin in people with stomach ulcers.

Table 3. Stomach parameters of non-ulcerated and ulcerated groups.

\begin{tabular}{|c|c|c|c|c|c|}
\hline \multirow[b]{2}{*}{ Parameters } & \multicolumn{5}{|c|}{ Groups } \\
\hline & $\begin{array}{l}\text { Control } \\
\text { normal }\end{array}$ & IND & $\mathbf{L F}+\mathbf{I N D}$ & MT+IND & $\mathbf{L F}+\mathbf{M T}+\mathbf{I N D}$ \\
\hline TNF- $\alpha$ (pg/g tissue) & $12.41^{\mathrm{a}} \pm 0.86$ & $39.21^{\mathrm{d}} \pm 0.57$ & $26.68^{\mathrm{bc}} \pm 1.47$ & $29.56^{c} \pm 0.90$ & $25.44^{\mathrm{b}} \pm 1.01$ \\
\hline NO (umol/g tissue) & $46.99^{\mathrm{a}} \pm 1.56$ & $59.76^{\mathrm{c}} \pm 1.42$ & $51.55^{\mathrm{b}} \pm 1.21$ & $50.75^{\mathrm{ab}} \pm 1.33$ & $48.26^{\mathrm{ab}} \pm 0.82$ \\
\hline MDA (nmol/g tissue) & $10.58^{\mathrm{a}} \pm 0.51$ & $28.82^{\mathrm{d}} \pm 0.90$ & $14.82^{\mathrm{b}} \pm 0.63$ & $17.00^{\mathrm{c}} \pm 0.58$ & $13.13^{\mathrm{b}} \pm 0.69$ \\
\hline GSH (mg/g tissue) & $22.34^{\mathrm{d}} \pm 0.67$ & $11.94^{\mathrm{a}} \pm 0.50$ & $15.04^{b} \pm 0.47$ & $18.46^{\mathrm{c}} \pm 0.48$ & $19.03^{\mathrm{c}} \pm 0.81$ \\
\hline SOD (U/g tissue) & $6.01^{\mathrm{b}} \pm 0.31$ & $4.32^{\mathrm{a}} \pm 0.30$ & $5.49^{\mathrm{b}} \pm 0.37$ & $5.56^{\mathrm{b}} \pm 0.22$ & $5.83^{\mathrm{b}} \pm 0.31$ \\
\hline
\end{tabular}

From the histopathological findings (Figure 4), it can be observed that the stomach tissue photomicrograph of non-ulcerated rats (Figure 4 (1A and $1 \mathrm{~B}$ )) was normal and the gastric mucosa was with normal thickness, the stomach tissue photomicrograph of IND rats (Figure 4 (2A)) showed gastric ulceration (stars) and other area of mucosa (rounded points) showed area of necrosis for mucosa cells also, the mucosa layer was thin when compared to the normal mucosa of control rat, the stomach tissue photomicrograph of IND rats (Figure 4 (2B)) showed gastric ulceration necrosis of mucosa (round points) and other area of mucosa (rounded points) showed cracks (small arrow) and cavitations (long arrow) of mucosa layer, the stomach tissue photomicrograph of IND rats (Figure $4(2 \mathrm{C})$ ) showed area of gastric ulceration (arrow head), the stomach tissue photomicrograph of IND rats (Figure 4 (2D)) showed necrosis of the epithelial cells (star) and area of cavitations between gastric glands was seen (arrow head), the stomach tissue photomicrograph of rat that pre-treated with lactoferrin (Figure 4 (3A)) before ulcer induction showed area of gastric crack ulceration (arrow) and the gastric mucosa was within normal thickness and arrangement and the higher magnification (Figure 4 (3B)) showed irregular crack in mucosa layer of stomach (arrow), the tissue photomicrograph tissue photomicrograph of rat that pre-treated with marjoram tea (Figure 4 (4A)) before ulcer induction showed little damage of surface mucous cells (star) and the higher magnification (Figure 4 (4B)) showed area of gastric crack (arrow) and the gastric mucosa showed irregular thickness while the stomach tissue photomicrograph of rats that pre-treated with lactoferrin and marjoram tea (Figure $4(5 \mathrm{~A})$ ) before ulcer induction showed the gastric mucosa within normal thickness and arrangement and the higher magnification (Figure 4 (5B)) showed that the gastric mucosa and gastric glands were within normal. 

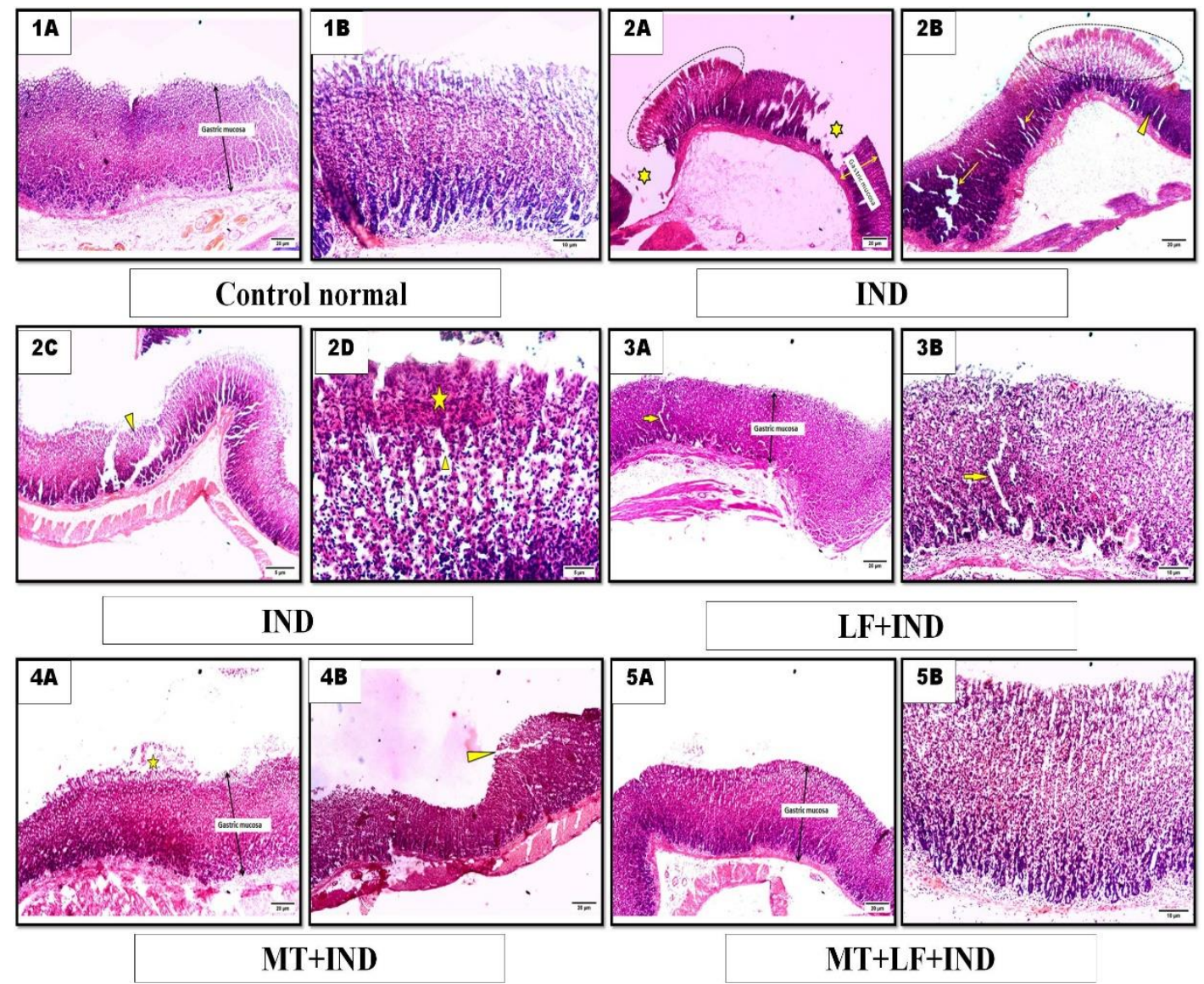

Figure 4. Stomach tissues' photomicrographs of non-ulcerated and ulcerated groups. (1A) gastric mucosa of control normal rats was normal; (1B) high magnification of gastric mucosa of control normal rats showed normal thickness; (2A and 2B) gastric mucosa of IND group showed gastric ulceration (stars) and other area of mucosa (rounded points) showed area of necrosis for mucosa cells; (2C and 2D) high magnification of gastric mucosa of IND group showed cracks (small arrow) and cavitations (long arrow) of mucosa layer; 3A, gastric mucosa of LF+IND group showed area of gastric crack ulceration (arrow); (3B) high magnification of gastric mucosa of LF+IND group showed irregular crack in mucosa layer of stomach (arrow); (4A); gastric mucosa of MT+IND group showed little damage of surface mucous cells (star); (4B) high magnification of gastric mucosa of MT+IND group showed area of gastric crack (arrow); (5A) gastric mucosa of MT+LF+IND group showed the gastric mucosa within normal thickness and arrangement; (5B) high magnification of gastric mucosa of $\mathrm{MT}+\mathrm{LF}+\mathrm{IND}$ group showed normal gastric mucosa and normal gastric glands (H\&E.X 40). IND, indomethacin; LF, lactoferrin; MT, marjoram tea.

\section{Conclusions}

The obtained results indicated the gastro-protective effect of lactoferrin, marjoram tea, and their mixture against indomethacin-induced gastric ulcers in rats. Lactoferrin, marjoram tea, and their mixture suppressed either the elevation in ferritin, TNF- $\alpha$, lipid peroxidation, and nitric oxide or the reduction in GSH and SOD after administration of indomethacin. Also, lactoferrin, marjoram tea, and their mixture showed notable improvement in the pathological findings of stomach tissue, emphasizing the superiority of lactoferrin alone or with marjoram tea in this concern.

\section{Funding}

This research received no external funding.

\section{Acknowledgments}

This study has no acknowledgment. 


\section{Conflicts of Interest}

The authors declare no conflict of interest.

\section{References}

1. Sharifi-Rad, M.; Fokou, P.V.T.; Sharopov, F.; Martorell, M.; Ademiluyi, A.O.; Rajkovic, J.; Salehi, B.; Martins, N.; Iriti, M.; Sharifi-Rad, J. Antiulcer agents: From plant extracts to phytochemicals in healing promotion. Molecules 2018, 23, 1751, https://doi.org/10.3390/molecules23071751.

2. Serafim, C.; Araruna, M.E.; Júnior, E.A.; Diniz, M.; Hiruma-Lima, C.; Batista, L. A Review of the Role of Flavonoids in Peptic Ulcer (2010-2020). Molecules 2020, 25, 5431, https://doi.org/10.3390/molecules25225431.

3. Zhang, W.; Lian, Y.; Li, Q.; Sun, L.; Chen, R.; Lai, X.; Lai, Z.; Yuan, E.; Sun, S. Preventative and Therapeutic Potential of Flavonoids in Peptic Ulcers. Molecules 2020, 25, 4626.

4. Dadfar, A.; Edna, T.H. Epidemiology of perforating peptic ulcer: A population-based retrospective study over 40 years. World Journal of Gastroenterology 2020, 26, 5302-5313, https://doi.org/10.3748/wjg.v26.i35.5302.

5. Ugwah, M.O.; Ugwah-Oguejiofor, C.J.; Etuk, E.U.; Bello, S.O.; Aliero, A.A. Evaluation of the antiulcer activity of the aqueous stem bark extract of Balanites aegyptiaca L Delile in Wistar rats. Journal of ethnopharmacology 2019, 239, 111931, https://doi.org/10.1016/j.jep.2019.111931.

6. Kuna, L.; Jakab, J.; Smolic, R.; Raguz-Lucic, N.; Vcev, A.; Smolic, M. Peptic ulcer disease: a brief review of conventional therapy and herbal treatment options. Journal of Clinical Medicine 2019, 8, 179, https://doi.org/10.3390/jcm8020179.

7. Sabra, S.; Agwa, M.M. Lactoferrin, a unique molecule with diverse therapeutical and nanotechnological applications. International Journal of Biological Macromolecules 2020, 164, 1046-1060. https://doi.org/10.1016/j.ijbiomac.2020.07.167

8. Li, X.; Li, Z.; Xu, E.; Chen, L.; Feng, H.; Chen, L.; Deng, L.; Guo, D. Determination of Lactoferrin in Camel Milk by Ultrahigh-Performance Liquid Chromatography-Tandem Mass Spectrometry Using an IsotopeLabeled Winged Peptide as Internal Standard. Molecules 2019, 24, 4199, https://doi.org/10.3390/molecules24224199.

9. Serrano, G.; Kochergina, I.; Albors, A.; Diaz, E.; Oroval, M.; Hueso, G.; Serrano, J.M. Liposomal lactoferrin as potential preventative and cure for COVID-19. International Journal of Research in Health Sciences 2020, 8, 8-15, https://doi.org/10.5530/ijrhs.8.1.3

10. Ciccaglione, A.F.; Di Giulio, M.; Di Lodovico, S.; Di Campli, E.; Cellini, L.; Marzio, L. Bovine lactoferrin enhances the efficacy of levofloxacin-based triple therapy as first-line treatment of Helicobacter pylori infection: an in vitro and in vivo study. Journal of Antimicrobial Chemotherapy 2019, 74, 1069-1077, https://doi.org/10.1093/jac/dky510.

11. Farouk, S.; Al-Huqail, A.A. Sodium nitroprusside application regulates antioxidant capacity, improves phytopharmaceutical production and essential oil yield of marjoram herb under drought. Industrial Crops and Products 2020, 158, 113034. https://doi.org/10.1016/j.indcrop.2020.113034

12. Hossain, M.B.; Brunton, N.P; Patras, A.; Tiwari, B.; O'donnell, C.P.; Martin-Diana, A.B.; Barry-Ryan, C. Optimization of ultrasound assisted extraction of antioxidant compounds from marjoram (Origanum majorana L.) using response surface methodology. Ultrasonics Sonochemestry 2012, 19, 582-590, https://doi.org/10.1016/j.ultsonch.2011.11.001.

13. Çelik, S.E.; Tufan, A.N.; Bekdesser, B.; Özyürek, M.; Güçlü, K.; Apak, R. Identification and determination ofphenolics in Lamiaceae species by UPLC-DAD-ESI-MS/MS. Journal of Chromatographic Science 2017, 55, 291-300, https://doi.org/10.1093/chromsci/bmw184.

14. Reeves, P.G.; Nielsen, F.H.; Fahey, G.C. AIN-93 Purified Diets for Laboratory Rodents: Final Report of the American Institute of Nutrition Ad Hoc Writing Committee on the Reformulation of the AIN-76A Rodent Diet. Journal of Nutrition 1993, 123, 1939-1951, https://doi.org/10.1093/jn/123.11.1939.

15. Abdel-Salam, A.M.; Alharbey, K.B.; Magzoub, M.A.; Mousa, H.M. Effect of heat treatment on the chromatographic detection, electrophoretic pattern and antibacterial activity of lactoferrin purified from camel milk. Journal of Food, Agriculture and Environment 2014, 12, 132-135.

16. Abdel-Salam, A.M.; Khattab, A.A.; Zahran, M.M.; Mahfouz, M.B.; Naim, Y.H. Biosynthesis of bovine lactoferrin in Saccharomyces cerevisiae and its anti-bacterial activity. Milchwissenschaft/Milk Science International 2006, 61, 14-18. 
17. Fecka, I.; Turek, S. Determination of polyphenolic compounds in commercial herbal drugs and spices from Lamiaceae: thyme, wild thyme and sweet marjoram by chromatographic techniques. Food Chemistry 2008, 108, 1039-1053, https://doi.org/10.1016/j.foodchem.2007.11.035.

18. Sabiu, S.; Garuba, T.; Sunmonu, T.; Ajani, E.; Sulyman, A.; Nurain, I.; Balogun, A. Indomethacin-induced gastric ulceration in rats: protective roles of Spondias mombin and Ficus exasperata. Toxicology Reports 2015, 2, 261-267, https://doi.org/10.1016/j.toxrep.2015.01.002.

19. Drabkin, D.I. The standardization of heamoglobin measurements. American Journal of Medical Sciences 1949, 21, 710 .

20. Stookey, L.L. Ferrozine-a new spectrophotometric reagent for iron. Analytical Chemistry 1970, 42, 779-781, https://doi.org/10.1021/ac60289a016.

21. Betts, C.A.; Stuart, B. Determination of serum total iron-binding capacity. Journal of Clinical Pathology 1973, 26, 457, https://doi.org/10.1136/jcp.26.6.457-a.

22. Zimmerman, H.J.; Weinstein, H.G. Lactic dehydrogenase activity in human serum. Journal of Laboratory and Clinical Medicine 1956, 48, 607-616.

23. Szabo, S.; Hollander, D. Pathways of gastrointestinal protection and repair: mechanisms of action of sucralfate. The American journal of medicine, 1989, 86, 23-31.

24. Ohkawa, H.; Ohishi, N.; Yagi, K. Assay for lipid peroxides in animal tissues by thiobarbituric acid reaction. Analytical Chemistry 1979, 95, 351-358, https://doi.org/10.1016/0003-2697(79)90738-3.

25. Montgomery, H.A.C.D.J.; Dymock, J.F. Determination of nitrite in water. Analyst 1961, 86(102), 414.

26. Sedlak, J.; Lindsay, R.H. Estimation of total, protein-bound and nonprotein sulfhydryl groups in tissue with Ellman's reagent. Analytical Chemistry 1968, 25, 192-205, https://doi.org/10.1016/0003-2697(68)90092-4.

27. Bjarnason, I.; Scarpignato, C.; Holmgren, E.; Olszewski, M.; Rainsford, K.D.; Lanas, A. Mechanisms of damage to the gastrointestinal tract from nonsteroidal anti-inflammatory drugs. Gastroenterology 2018, 154, 500-514, https://doi.org/10.1053/j.gastro.2017.10.049.

28. Arab, S.; Rezaee, K.; Moghaddam, G. A novel fuzzy expert system design to assist with peptic ulcer disease diagnosis. Cogent Engineering 2021, 8, 1861730, https://doi.org/10.1080/23311916.2020.1861730.

29. Akl, E.M.; Taha, F.S.; Mohamed, S.S.; Mohamed, R.S. Characterization of Garden Cress Mucilage and its Prophylactic Effect Against Indomethacin-Induced Enter-Colitis in Rats. Biointerferance Research in Applied Chemistry 2021, 11, 13911 - 13923, https://doi.org/10.33263/BRIAC116.1391113923.

30. Maseda, D.; Ricciotti, E. NSAID-Gut Microbiota Interactions. Fronters in Pharmacology 2020, 11, 1153, https://doi.org/10.3389/fphar.2020.01153.

31. Ghosh, R.; Alajbegovic, A.; Gomes, A.V. NSAIDs and cardiovascular diseases: role of reactive oxygen species. Oxidative Medicine and Cellular Longevity 2015, 2015, 536962, https://doi.org/10.1155/2015/536962.

32. Lepanto, M.S.; Rosa, L.; Paesano, R.; Valenti, P.; Cutone, A. Lactoferrin in aseptic and septic inflammation. Molecules 2019, 24, 1323, https://doi.org/10.3390/molecules24071323.

33. Pimple, B.P.; Kadam, P.V.; Patil, M.J. Ulcer healing properties of different extracts of Origanum majorana in streptozotocin-nicotinamide induced diabetic rats. Asian Pacific Journal of Tropical Disease 2012, 2, 312318, https://doi.org/10.1016/s2222-1808(12)60068-1.

34. Ahmad, B.A.; Rao, M.U.; Muhammad, A.; Zin, T.; Mohamad, N.H.; Mohamad, N.; Mohd, K.S. Reviews of herbal and their secondary metabolites in the treatment of ulcerative colitis and peptic ulcer. Journal of Applied Pharmaceutical Science 2014, 4, 080-090, https://doi.org/10.7324/JAPS.2014.40817.

35. Goineau, S.; Castagné, V. Complementarity of in vitro and in vivo models for the evaluation of gastroprotective effects of pharmacological substances. Fundamental and Clinical Pharmacology 2017, 31, 155164. https://doi.org/10.1111/fcp.12248.

36. Kell, D.B.; Pretorius, E. Serum ferritin is an important inflammatory disease marker, as it is mainly a leakage product from damaged cells. Metallomics 2014, 6, 748-773, https://doi.org/10.1039/c3mt00347g.

37. Pulina, M.; Sokolov, A.; Zakharova, E.; Kostevich, V.; Vasilyev, V. Effect of lactoferrin on consequences of acute experimental hemorrhagic anemia in rats. Bulletin of Experimental Biology and Medicine 2010, 149 , 219-222, https://doi.org/10.1007/s10517-010-0911-6.

38. Jungmi, K.; Hyun-Dong, P.; Yoh-Chang, Y.; Eunju, P. Whey protein inhibits iron overload-induced oxidative stress in rats. Journal of Nutritional Science and Vitaminology 2013, 59, 198-205, https://doi.org/10.3177/jnsv.59.198. 
39. Hu, P.; Zhao, D.; Zhao, F.; Wang, J.; Zhu, W. The effects of the combination of oral lactoferrin and iron injection on iron homestasis, antioxidative abilities and cytokines activities of suckling piglets. Animals 2019, 9, 438. https://doi.org/10.3390/ani9070438.

40. Kim, C.W.; Lee, T.H.; Park, K.H.; Choi, S.Y.; Kim, J. Human lactoferrin suppresses TNF- $\alpha$-induced intercellular adhesion molecule-1 expression via competition with NF- $\mathrm{BB}$ in endothelial cells. FEBS Letters 2012, 586, 229-234, https://doi.org/10.1016/j.febslet.2011.12.011.

41. Kell, D.B.; Heyden, E.L.; Pretorius, E. The Biology of Lactoferrin, an Iron-Binding Protein That Can Help Defend Against Viruses and Bacteria. Fronters in Immunology 2020, 11, 1221. https://doi.org/10.3389/fimmu.2020.01221.

42. Wang, Y.; Xu, C.; An, Z.; Liu, J.; Feng, J. Effect of dietary bovine lactoferrin on performance and antioxidant status of piglets. Animal Feed Science and Technology 2008, 140, 326-336, https://doi.org/10.1016/j.anifeedsci.2007.02.006.

43. Han, N.; Li, H.; Li, G.; Shen, Y.; Fei, M.; Nan, Y. Effect of bovine lactoferrin as a novel therapeutic agent in a rat model of sepsis-induced acute lung injury. Express $A M B$ 2019, 9, 177, https://doi.org/10.1186/s13568019-0900-8.

44. Lepanto, M.S.; Rosa, L.; Cutone, A.; Conte, M.P.; Paesano, R.; Valenti, P. Efficacy of Lactoferrin Oral Administration in the Treatment of Anemia and Anemia of Inflammation in Pregnant and Non-pregnant Women: An Interventional Study. Frontiers in immunology 2018, 9, 2123, https://doi.org/10.3389/fimmu.2018.02123.

45. Sverdén, E.; Agréus, L.; Dunn, J.M.; Lagergren, J. Peptic ulcer disease. BMJ 2019, 367, 15495.

46. Wiciński, M.; Liczner, G.; Cadelski, K.; Kołnierzak, T.; Nowaczewska, M.; Malinowski, B. Anemia of Chronic Diseases: Wider Diagnostics_Better Treatment? Nutrients 2020, 12, 1784, https://doi.org/10.3390/nu12061784.

47. Rockey, D.C.; Altayar, O.; Falck-Ytter, Y.; Kalmaz, D. AGA Technical Review on Gastrointestinal Evaluation of Iron Deficiency Anemia. Gastroenterology 2020, 159, 1097-1119, https://doi.org/10.1053/j.gastro.2020.06.045. 